\title{
Electrochemical Biomineralization: the Deposition of Calcite with Chiral Morphologies
}

\section{Supporting Information}

\author{
Elizabeth A. Kulp and Jay A. Switzer* \\ Department of Chemistry and Graduate Center for Materials Research, University of Missouri-Rolla, \\ Rolla, Missouri 65409-1170, USA \\ jswitzer@umr.edu
}

\section{Electrochemical Deposition}

The calcium carbonate films were deposited at $30{ }^{\circ} \mathrm{C}$ using a constant potential of $-1.1 \mathrm{~V}$ vs. $\mathrm{Ag} / \mathrm{AgCl}$ for 1800-3600 s. The argon purged deposition solution consisted of $4.1 \mathrm{mM} \mathrm{CaCl} \mathrm{m}_{2} * 2 \mathrm{H}_{2} \mathrm{O}$ and $7.1 \mathrm{mM}$ $\mathrm{NaHCO}_{3}$ with additive concentrations of $3.2 \mathrm{mM} \mathrm{MgCl}_{2}, 2.5 \mathrm{mM}$ of succinic acid, $2.0 \mathrm{mM}$ of the enantiomer of tartaric acid, $2.2 \mathrm{mM}$ of the enantiomer and racemic malic acid, or $4.5 \mathrm{mM}$ of the enantiomer of aspartic acid. All of the films were deposited onto stainless steel substrates.

\section{Characterization Techniques}

Grazing incidence X-ray diffraction patterns were run on a high-resolution Philips X'Pert MRD diffractometer using $\mathrm{CuK}_{\alpha}$ source radiation with an X-ray mirror as the incident beam module and $0.18^{\circ}$ parallel plate collimator as the diffracted beam module. A fixed incident angle of $1^{\circ}$ was maintained. Stereographic projections were simulated for the calcite crystal structure using CaRIne 3.1 software. SEM images were obtained on uncoated samples using a Hitachi S-4700 cold field-emission scanning electron microscope with an EDAX energy dispersive x-ray unit for elemental analysis. 


\section{Symmetry Aspects of Chirality for the Calcite Crystal Structure}

The chiral nature of calcite planes is easily visualized in stereographic projections. A stereographic projection is a two-dimensional plot that shows the angular relationships of the crystal's faces based on its crystallographic symmetry. As seen in Figures $1 \mathrm{aS}$ and $1 \mathrm{bS}$, the stereographic projections of $(10 \overline{1} 4)$ and $(\overline{1} 01 \overline{4})$ are superimposable mirror images of each other. Therefore, these planes are achiral. However, the nonsuperimposable stereographic projections of the $(11 \overline{2} 0)$ and $(\overline{1} \overline{1} 20)$ orientations and the $(21 \overline{3} 1)$ and $(\overline{2} \overline{1} 3 \overline{1})$ orientations of calcite show that they are enantiomers of each other (Figures $1 \mathrm{cS}, 1 \mathrm{dS}, 1 \mathrm{eS}$, and $1 \mathrm{fS}$, respectively).

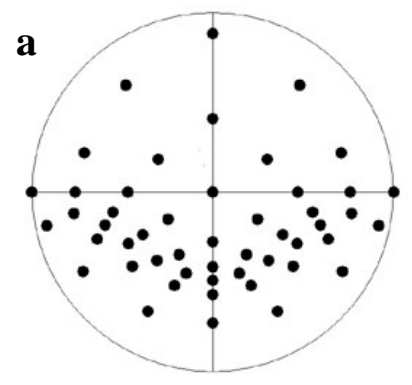

$(10 \overline{1} 4)$

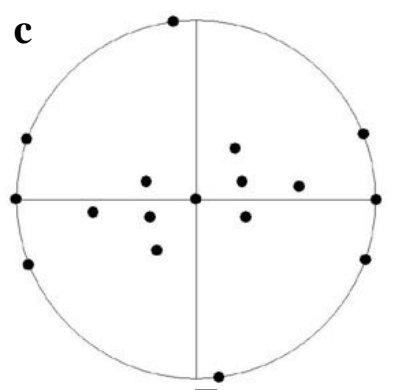

(1120)

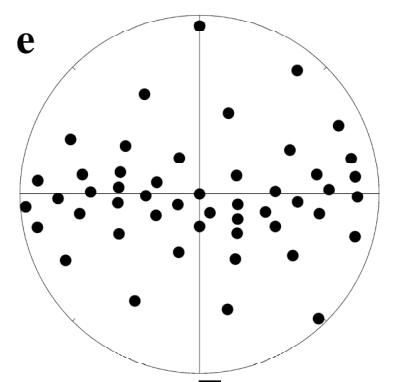

$(21 \overline{3} 1)$

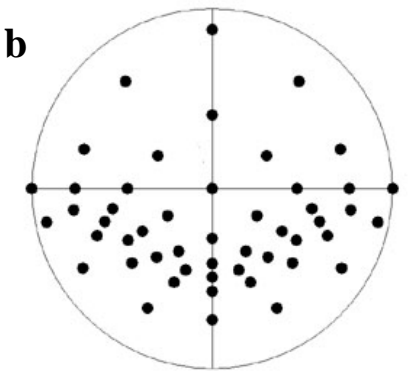

$(\overline{1} 01 \overline{4})$

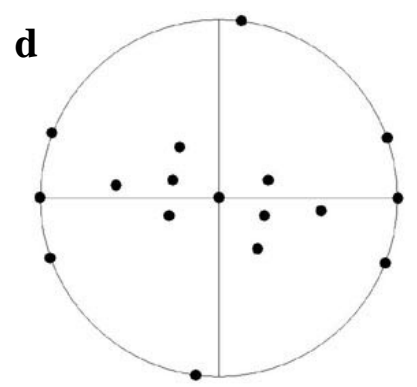

$(\overline{1} \overline{1} 20)$

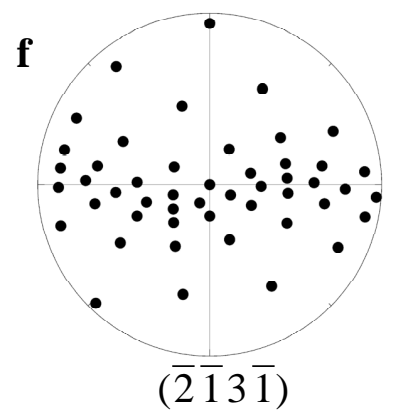


Figure 1S Stereographic projections of achiral and chiral orientations of calcite. The orientations (a) $(10 \overline{1} 4)$ and (b) $(\overline{1} 01 \overline{4})$ are achiral because the two stereographic projections have mirror symmetry and are superimposable. The orientations (c) $(11 \overline{2} 0)$ and (d) $(\overline{1} \overline{1} 20)$ as well as (e) (21 $\overline{3} 1)$ and (f) $(\overline{2} \overline{1} 3 \overline{1})$ are chiral because the two stereographic projections lack mirror symmetry and are not superimposable. 